\title{
Uncatalyzed gas phase aziridination of alkenes by organic azides. Part 2. Whole azide reaction with alkene
}

\author{
S PREMILA DEVI and R H DUNCAN LYNGDOH* \\ Department of Chemistry, North-Eastern Hill University, Shillong, Meghalaya 793 022, India \\ E-mail: rhdl@nehu.ac.in
}

MS received 13 September 2018; revised 17 October 2018; accepted 20 October 2018; published online 4 January 2019

\begin{abstract}
The B3LYP/6-31G(d,p) DFT method was used to study alkene aziridination by azides through uncatalyzed thermal gas phase routes which involve the whole azide reactant molecule without dissociation. Two mechanisms were studied - Route I involving concerted azide addition to alkene with the elimination of $\mathrm{N}_{2}$, and the multi-step Route II involving 1,3-dipolar cycloaddition between azide and alkene. Three azides $\mathbf{R N}_{3}(\mathbf{R}=\mathrm{H}, \mathrm{Me}, \mathrm{Ac})$ are reacted with alkene substrates forming aziridine products. The concerted additionelimination step of Route I is exothermic with an appreciable barrier, where the facility order $\mathrm{Ac}>\mathrm{Me}>\mathrm{H}$ points to electrophilicity of the azide reactant. The initial 1,3-dipolar cycloaddition step of Route II involves smaller barriers than Route I, while thermal decomposition of the triazoline intermediate to aziridine and $\mathrm{N}_{2}$ involves two more steps with an $\mathrm{N}$-alkylimine intermediate. The very high barrier for $\mathrm{N}$-alkylimine cyclization to aziridine could be offset by the high exothermicity of the previous step. Geometries of the transition states for various reaction steps studied here are described as 'early' or 'late' in good accordance with the Hammond postulate. Two other mechanisms (Routes A and B) studied earlier (involving discrete nitrene intermediates) are compared with Routes I and II, where Route II involving 1,3-dipolar cycloaddition is predicted to be energetically the most favored of all the four mechanisms for thermal gas-phase aziridination of alkenes by azides.
\end{abstract}

Keywords. Alkene aziridination by azides; 1,3-dipolar cycloaddition; triazoline decomposition; density functional theory.

\section{Introduction}

Nitrene addition to a $\mathrm{C}=\mathrm{C}$ double bond is one strategy for aziridine synthesis, ${ }^{1,2}$ using substrates including alkenes and fullerenes. ${ }^{3,4}$ Azides are prominent as carriers of the nitrene moiety, which may be written as $-\mathrm{NR}$ or :NR for the free nitrene. ${ }^{5,6}$ A noteworthy aspect of aziridine synthesis is asymmetric aziridination ${ }^{7,8}$ which includes a variety of substrates, reagents and catalysts. ${ }^{9-14}$ This paper, however, considers only the bare, thermal, uncatalyzed aziridination reaction in the gas phase. In this context, whether alkene aziridination involves nitrenes as a discrete species or as a transferred moiety is a question of interest. An earlier computational study ${ }^{15}$ considered the possibility of free nitrene species participating in this reaction. The present study treats the whole (undissociated) azide molecules as nitrene transfer agents for alkene aziridination.

\subsection{Mechanisms for alkene aziridination by azides}

Two mechanisms for alkene aziridination by whole azide molecules are considered here. Route I, proposed for the first time, involves the concerted addition of azide to alkene with the elimination of $\mathrm{N}_{2}$. Route II involves the well-known 1,3-dipolar cycloaddition of azide to alkene, followed by decomposition of the triazoline intermediate to the aziridine releasing $\mathrm{N}_{2}$. Which route is more feasible is predicted here computationally, and then compared with the two earlier routes ${ }^{15}$ involving the participation of discrete nitrene species.

Three azide reactants are considered here - hydrazoic acid $\mathrm{HN}_{3}$, methyl azide $\mathrm{MeN}_{3}$ and acetyl azide $\mathrm{AcN}_{3}$ (Figure 1) - in order to examine the effects of change in the $\mathbf{R}$ group of the azide $\mathbf{R N}_{3}$. The nitrene moiety transferred during aziridination is $\mathbf{R N}-(\mathbf{R}=$ $\mathrm{H}, \mathrm{Me}$ and $\mathrm{Ac})$. Four alkene substrates ethene, propene,

\footnotetext{
*For correspondence

Electronic supplementary material: The online version of this article (https://doi.org/10.1007/s12039-018-1575-4) contains supplementary material, which is available to authorized users.
} 


$$
\begin{aligned}
& \mathrm{H}-\mathrm{N}=\stackrel{\oplus}{\mathrm{N}}=\stackrel{\ominus}{\mathrm{N}} \\
& \text { hydrazoic acid } \\
& \begin{array}{c}
\mathrm{H}_{3} \mathrm{C}-\mathrm{N}=\stackrel{\oplus}{\mathrm{N}}=\stackrel{\ominus}{\mathrm{N}} \\
\text { methyl azide }
\end{array} \\
& \begin{array}{c}
\stackrel{\mathrm{O}}{\mathrm{H}} \mathrm{C}-\stackrel{\oplus}{\mathrm{C}}-\mathrm{N}=\stackrel{\oplus}{\mathrm{N}}=\stackrel{\ominus}{\mathrm{N}} \\
\text { acetyl azide }
\end{array} \\
& \mathrm{H}_{2} \mathrm{C}=\mathrm{CH}_{2} \\
& \stackrel{\mathrm{C}=\mathrm{C}^{\prime}}{\mathrm{H}}{ }_{\mathrm{H}}^{\mathrm{H}} \\
& { }_{\text {cis but-2-ene }}^{\mathrm{H}^{\mathrm{C}=\mathrm{C}^{\prime}}}{ }_{\mathrm{H}}^{\mathrm{C}_{3} \mathrm{CH}_{3}}
\end{aligned}
$$

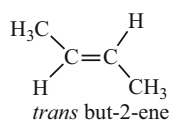

Figure 1. Azides as nitrene transfer agents and alkenes as substrates for aziridination.

(a)
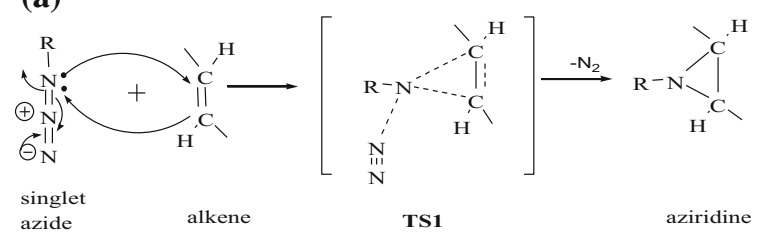

(b)
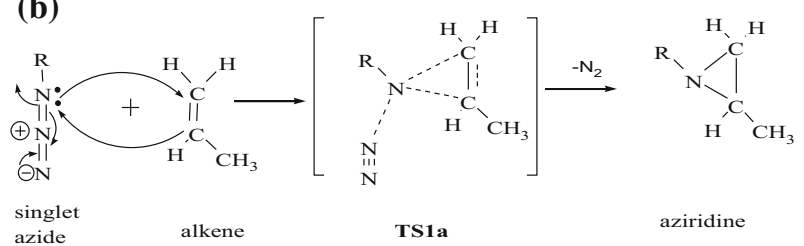

(c)

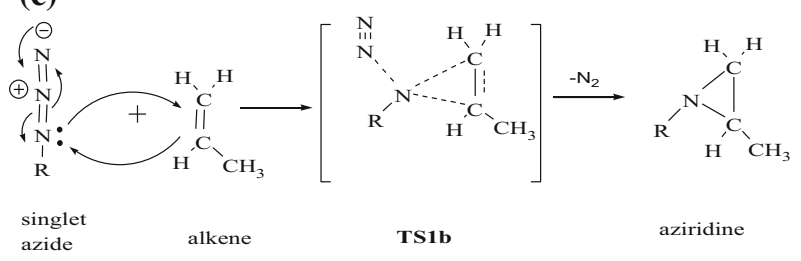

Figure 2. Mechanisms for (a) concerted addition-elimination aziridination of alkene (trans-2-butene as an example) by azide, along with (b) propene A case, and (c) propene B case.

cis- and trans-2-butene (Figure 1) are chosen to study the effects of successive methyl substitution.

Route I (Figure 2) is concerted, where the $\mathbf{R}-\mathrm{N}$ moiety of the azide attacks the alkene $\mathrm{C}=\mathrm{C}$ bond with loss of $\mathrm{N}_{2}$, proceeding via transition state TS1. For ethene, cis- and trans-2-butene, there is only one energetically unique orientation for the approach of the azide to the alkene. For the asymmetrical propene case, there are two orientations (Figures $2 \mathrm{~b}$ and $2 \mathrm{c}$ ), with the azide $\mathbf{R}$ group pointing away from and towards the propene methyl group, proceeding through transition states TS1a and TS1b respectively (the propene A and propene B cases).

Route II has two phases. The first phase (Figure 3) is concerted 1,3-dipolar cycloaddition of singlet azide to the alkene. This thermal pericyclic reaction proceeds via transition state TS2 to yield the 1,2,3-triazoline intermediate. The asymmetrical propene gives two orientations (propene A and propene B) shown in Figures $3 \mathrm{~b}$ and 3c, where the azide $\mathbf{R}$ group points towards and away from (a)

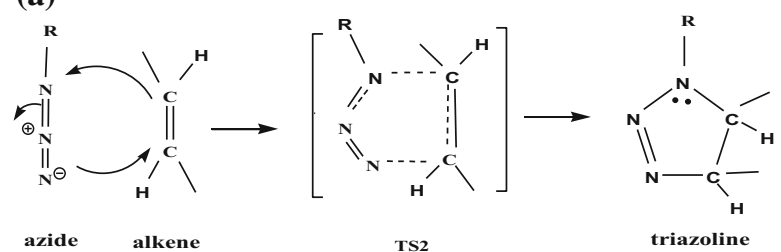

(b)

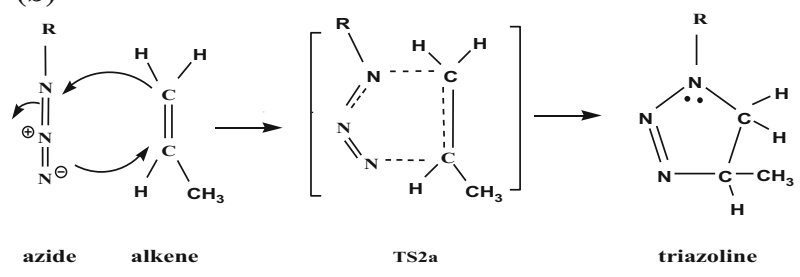

(c)
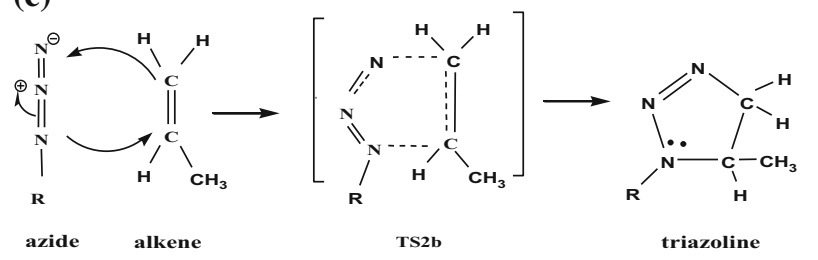

Figure 3. First phase of Route II: 1,3-dipolar cycloaddition of azide to alkene (trans-2-butene as an example), showing also (b) propene A case, and (c) propene B case.

the methyl group, proceeding via transition states TS2a and TS2b.

1,3-Dipolar cycloaddition (the first step of Route II) has wide synthetic utility. ${ }^{16,17}$ The Huisgen 1,3dipolar cycloaddition ${ }^{18}$ between azides and alkynes yields 1,2,3-triazole products, well-known as a metalcatalyzed reaction. ${ }^{19}$ This reaction is of much importance for click chemistry, ${ }^{20}$ and has been employed to enable live cell imaging. ${ }^{21}$ However, such a reaction between azides and alkenes has not been studied as much and is mentioned here for its relevance to aziridine synthesis.

In the second phase of Route II (Figure 4), the intermediate formed in the first phase undergoes 1,2-hydride shift to yield an acyclic intermediate with loss of $\mathrm{N}_{2}$ via transition state TS3. Subsequent ring closure through 1,2-hydride shift leads to the aziridine product via transition state TS4. For the first step of this second phase, the propene case may have the $\mathbf{R}$ group pointing towards and away from the propene methyl group, proceeding via transition states TS3a and $\mathbf{T S 3} \mathbf{b}$ respectively (Figures $4 \mathrm{~b}$ and $4 \mathrm{c}$ ). The two $\mathrm{N}$-alkylimine products formed rearrange to give two different final aziridine products via the transition states TS4a and TS4b respectively. These two aziridines may interconvert via inversion at the $\mathrm{N}$-atom, but this may involve a barrier not easily overcome at room temperature. 
(a)
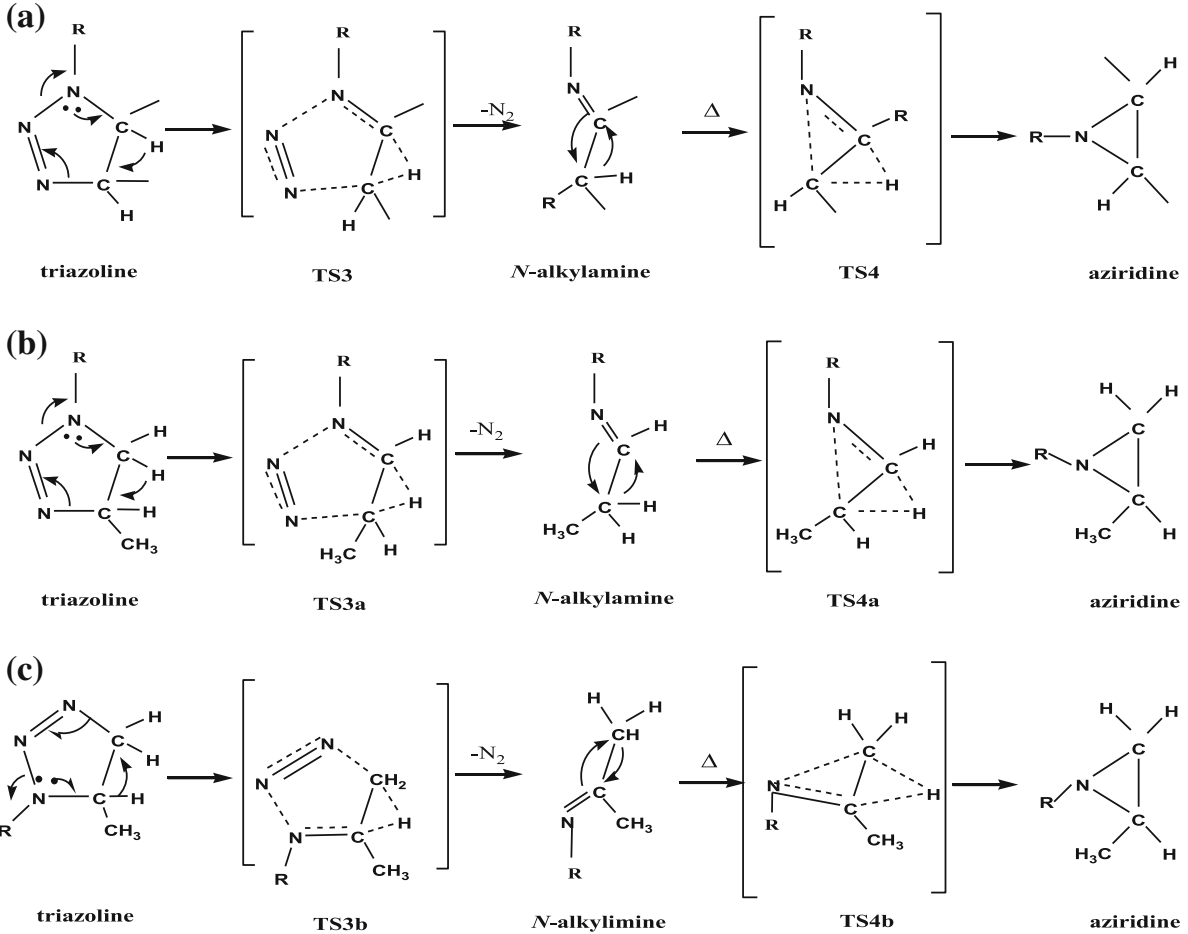

Figure 4. Second phase of Route II - the two-step decomposition of 1,2,3-triazoline to aziridine and $\mathrm{N}_{2}$ via an $\mathrm{N}$-alkylimine intermediate, along with (b) the propene A case, and (c) the propene B case.

\subsection{1,3-Dipolar cycloadditions with azides}

A CBS-QB3 study on cycloadditions of alkenes and ynamines with 1,3-dipoles yielded trends in activation barrier values and regioselectivity. ${ }^{22,23}$ A B3LYP and SCS-MP2 study on regioselectivity of cycloadditions of azides to cyclic alkynes and alkenes ${ }^{24}$ treated the effects of fluorine substitution, strain, ring size and multiple bond type. Such effects in metal-free azidealkyne click reactions were studied in the context of biological processes. ${ }^{25}$ A B3LYP study described substituent effects on transition states for the aziridination of various alkenes by oxaziridines and diaziridinum salts. ${ }^{26}$ Cycloaddition of benzyl azide to acrylic acid was studied by the B3LYP method. ${ }^{27}$ Strain energies and hydrogenation enthalpies for cyclic alkynes and alkenes, computed by the G3 method, were correlated with activation barriers for cycloaddition between various azides and these substrates. ${ }^{28}$ A DFT-cumexperimental study on reactions between aryl azides and activated alkenes ${ }^{29}$ rationalized regioselectivity trends. 1,3-Dipolar cycloaddition of methyl azide to $\mathrm{C}_{60}$ with stepwise $\mathrm{N}_{2}$ elimination from the intermediate to yield the aziridine was studied using the AM1 and DFT methods. ${ }^{30}$

Aziridination of aldimines by sulfur ylides was studied by DFT to study substituent effects upon diastereoselectivity. ${ }^{31}$ A DFT study on aziridine formation from guanidinium ylide and $\mathrm{p}$-substituted benzaldehydes predicted substituent effects upon diastereoselectivity. ${ }^{32}$ Mechanistic studies using DFT on aziridination with arsenic ylides identified the roles of steric and electrostatic interactions for diastereoselectivity. ${ }^{33}$ Mechanisms of ring opening for aziridines and for boriranes have been compared using ab initio and DFT approaches. ${ }^{34}$

\subsection{Scope and objectives of the study}

In this study, the undissociated azide molecule as a whole acts as the aziridinating agent, not the free nitrene as studied earlier. ${ }^{15}$ Three azides $\mathbf{R}-\mathrm{N}_{3}$ are taken as nitrene transfer agents $[\mathbf{R}=\mathrm{H}, \mathrm{Me}$ and Ac (acetyl)] and four alkenes (ethene, propene, cis- and trans-2-butene) as substrates (Figure 1). Two routes are considered here, viz., (a) concerted addition-elimination of the azide $\mathbf{R}-\mathrm{N}_{3}$, called Route I, and (b) a two-phase pathway involving 1,3-dipolar cycloaddition and decomposition of a triazoline intermediate, called Route II. The aims of this study are as follows:

1 . To discern the effects of (a) change in the $\mathbf{R}$ group of the azide reactant $\mathbf{R} \mathrm{N}_{3}$ and (b) methyl substitution in the alkene substrates for aziridination facility. For each 
concerted step, the activation barrier and accompanying energy change represent are used to indicate facility.

2. To correlate transition state geometry with reaction energetics as per the Hammond postulate for the various one-step reactions studied here.

3. To predict the most feasible of the four distinct routes for alkene aziridination by azides, viz., Routes I and II, along with two other mechanisms studied earlier involving discrete nitrene intermediates. ${ }^{15}$

\section{Computational methods and strategy}

The B3LYP DFT method ${ }^{35,36}$ with a $6-31 G^{* *}$ basis set was used to study the two routes proposed above. Vibrational frequency analysis characterized all species either as energy minima or transition states. Zero point vibrational energies (ZPE) were corrected by a scaling factor of 0.9806 prescribed for the B3LYP/6-31G(d,p) strategy. ${ }^{37}$ All computations were carried out using the Gaussian 2009 program. ${ }^{38}$

Transition states were located by interpolation between reactant and product geometries. For steps with two reactants, an entry complex was set up keeping a constant non-bonded distance between the appropriate atoms and optimizing other internal coordinates. Likewise, steps yielding two products were treated by setting up an initial exit complex.

Energetics were monitored by estimating the energy change for any one step (denoted as $\Delta E_{r}$ or $\Delta G_{r}$ for the enthalpy or free energy change respectively), and also the activation barrier (denoted as $\Delta E^{\ddagger}$ and $\Delta G^{\ddagger}$ in enthalpy and free energy terms respectively). The net reaction given below for aziridination of alkene by azide is associated with the net enthalpy change $\Delta E_{R}$ (or net free energy change $\Delta G_{R}$ ), independent of the mechanism.

$\mathrm{R}-\mathrm{N}_{3}+>\mathrm{C}=\mathrm{C}<\longrightarrow$ aziridine $+\mathrm{N}_{2}+\Delta E_{R}\left(\operatorname{or} \Delta G_{R}\right)$

azide alkene product

For both Route I and Route II, an energy profile is plotted setting the energy level of the initial reactants as zero and including all stages along the pathway. This was also done for the two routes of the earlier DFT study ${ }^{15}$ which involved discrete nitrene species. This is done to predict the energetically most feasible option among the four mechanisms proposed.

Transition state geometries are examined for the effects of the azide $\mathbf{R}$ groups and alkene substituents, and to relate transition state geometry to the Hammond postulate. ${ }^{39}$ This states that for reactions with a modest barrier, exothermic reactions proceed via 'early' transition states which resemble the reactants in geometry and energy. Endothermic reactions have 'late' transition states which resemble the products.

Figure 5 depicts select geometry parameters for the transition states (a) TS1 for concerted addition-elimination of azide to alkene (Route I), (b) TS2 for 1,3-dipolar cycloaddition between azide and alkene (first phase of Route II), (c) TS3 for 1,2-hydride shift in triazoline to form $\mathrm{N}$-alkylimine intermediate (initial step of second phase of Route II), and (a)

(b)

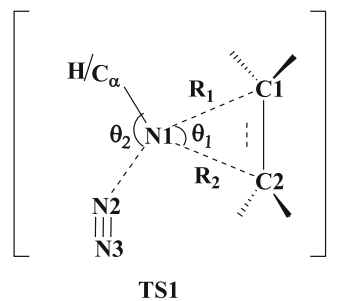

(c)

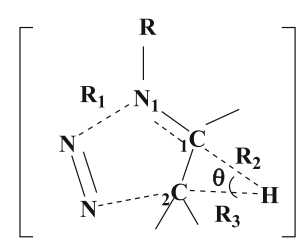

TS3

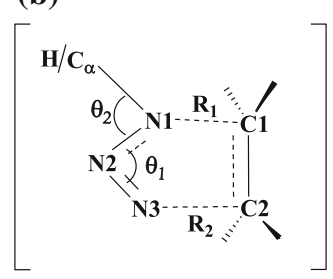

TS2

(d)

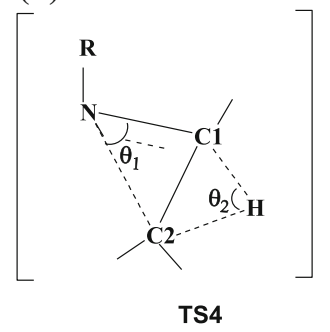

Figure 5. Geometry parameters for transition states. (a) TS1 for concerted addition-elimination of azide to alkene, (b) TS2 for 1,3-dipolar cycloaddition between azide and alkene, (c) TS3 for 1,2-hydride shift in triazoline to form $\mathrm{N}$-alkylimine, and (d) TS4 for conversion of N-alkylimine to aziridine by another 1,2-hydride shift.

(d) TS4 for conversion of $\mathrm{N}$-alkylimine to the aziridine cycle by another 1,2-hydride shift (second step of second phase of Route II). These geometry parameters relate transition state geometry to the Hammond postulate and estimate position of the transition state along the reaction pathway.

\section{Results and Discussion}

Route I and Route II for the thermal, gas phase, uncatalyzed aziridination of alkenes by whole azide molecules are discussed as follows:

\subsection{Concerted aziridination by azide (Route I)}

This one-step mechanism for alkene aziridination (Figure 2) has not yet been studied before. Table 1 lists B3LYP values of the energy changes and activation barriers for this step.

The reaction energy changes $\Delta E_{R}$ and $\Delta G_{R}\left(\Delta E_{R}\right.$ always smaller in magnitude than $\Delta G_{R}$ ) predict appreciable exothermicity $\left(\Delta E_{R}\right.$ from -42.0 to $-49.5 \mathrm{kcal} / \mathrm{mol}$ ). In general, the trend for a thermodynamic facility with respect to azide substituent $\mathbf{R}$ falls in the order $\mathrm{H}<\mathrm{Me}<\mathrm{Ac}$. This points to the electrophilic character of the azide reactant as it reacts with the alkene, where the electron-withdrawing acetyl substituent in the acyl azide enhances reaction facility. 
Table 1. B3LYP/6-31G** values of energy parameters* for concerted aziridination of alkenes by Route I (direct action of azide $\mathbf{R}-\mathrm{N}_{3}$ upon alkene via TS1; Figure 2).

\begin{tabular}{lllll}
\hline Alkene & $\Delta E_{R}$ & $\Delta E^{\ddagger}$ & $\Delta G_{R}$ & $\Delta G^{\ddagger}$ \\
\hline $\mathbf{R}=\mathbf{H}$ & & & & \\
Ethene & -42.0 & 38.2 & -40.8 & 47.0 \\
Propene A & -42.5 & 37.4 & -40.3 & 47.4 \\
Propene B & -42.2 & 37.7 & -39.9 & 47.6 \\
cis-2-Butene & -43.5 & 36.4 & -41.3 & 46.0 \\
trans-2-Butene & -43.0 & 36.9 & -40.6 & 47.0 \\
$\mathbf{R}=\mathbf{M e}$ & & & & \\
Ethene & -44.3 & 38.5 & -42.1 & 50.1 \\
Propene A & -44.9 & 38.1 & -41.7 & 50.3 \\
Propene B & -41.8 & 38.2 & -38.2 & 52.2 \\
cis-2-Butene & -46.0 & 41.2 & -42.8 & 51.0 \\
trans-2-Butene & -42.7 & 43.2 & -39.4 & 52.2 \\
R $=$ Ac & & & & \\
Ethene & -47.2 & 38.4 & -46.2 & 49.5 \\
Propene A & -48.1 & 33.2 & -46.1 & 43.4 \\
Propene B & -46.7 & 35.8 & -46.0 & 44.2 \\
cis-2-Butene & -49.5 & 31.5 & -47.4 & 41.7 \\
trans-2-Butene & -47.8 & 32.5 & -45.5 & 42.2 \\
\hline
\end{tabular}

*All energy terms in $\mathrm{kcal} / \mathrm{mol}$.

The activation barrier $\Delta E^{\ddagger}$ ranges from 31.5 to $43.2 \mathrm{kcal} / \mathrm{mol}$, and the free energy barrier $\Delta G^{\ddagger}$ higher than $\Delta E^{\ddagger}$ by 9 to $11 \mathrm{kcal} / \mathrm{mol}$, the correlation between the two being shown in Figure S1 (Supplementary Information). For $\mathrm{HN}_{3}$ and $\mathrm{AcN}_{3}, \Delta E^{\ddagger}$ follows the order: ethene $>$ propene $>$ trans-2-butene $>$ cis-2butene. Successive methyl substitution in the alkene lowers the barrier, showing the electrophilic nature of the azide. For propene, orientation A is favored over B, due to lesser steric interactions.

Direct attack of azide on alkene is compared with the rate-determining step for Route A studied earlier, viz., decomposition of azide to singlet nitrene. ${ }^{15}$ Direct attack of $\mathrm{HN}_{3}$ gives activation barriers (36.4 to $38.2 \mathrm{kcal} / \mathrm{mol}$ ) lower than the barrier for decomposition of $\mathrm{HN}_{3}$ to $\mathrm{NH}$ $(52.7 \mathrm{kcal} / \mathrm{mol})$, so Route I is predicted more feasible than the rate-limiting step of Route A. For $\mathrm{MeN}_{3}$, the barrier for decomposition to $\mathrm{MeN}(39.4 \mathrm{kcal} / \mathrm{mol})$ is comparable to the barriers involved in Route I (38.1 to $43.2 \mathrm{kcal} / \mathrm{mol}$ ), so that these two pathways could compete. For $\mathrm{AcN}_{3}$, the barriers to direct attack (31.5 to $38.4 \mathrm{kcal} / \mathrm{mol}$ ) are higher than the barrier for $\mathrm{AcN}_{3}$ decomposition to $\mathrm{AcN}(28.1 \mathrm{kcal} / \mathrm{mol})$, so that Route $\mathrm{A}$ is favored.

B3LYP values of geometry parameters for TS1 (Figure 5a) are given in Table S1 (SI). The two forming $\mathrm{N}-\mathrm{C}$ bond lengths $R_{1}$ and $R_{2}(2.199$ to $2.825 \AA$ ) are shorter than the length $R_{3}$ of the breaking bond between the $\mathrm{N} 1$ atom and the escaping $\mathrm{N}_{2}$ moiety (1.647
Table 2. B3LYP/6-31G** values for energy parameters* associated with 1,3-dipolar cycloaddition of azide $\mathbf{R}-\mathrm{N}_{3}$ to alkene (Figure 3) via transition state TS2.

\begin{tabular}{lccccc}
\hline Alkene & $\Delta E_{r}$ & $\Delta E^{\ddagger}$ & $\Delta G_{r}$ & $\Delta G^{\ddagger}$ & $v_{i}$ \\
\hline $\mathbf{R}=\mathbf{H}$ & & & & & \\
Ethene & -15.4 & 20.6 & -2.9 & 31.9 & -452.0 \\
Propene A & -14.4 & 21.9 & -0.7 & 34.0 & -444.4 \\
Propene B & -14.4 & 22.3 & -0.6 & 34.5 & -450.9 \\
cis-2-Butene & -14.4 & 23.3 & -0.3 & 35.3 & -442.9 \\
trans-2-Butene & -14.0 & 23.4 & -0.0 & 35.6 & -437.5 \\
$\mathbf{R}=\mathbf{M e}$ & & & & & \\
Ethene & -18.9 & 19.0 & -5.5 & 30.6 & -406.6 \\
Propene A & -17.8 & 20.6 & -3.3 & 33.3 & -405.9 \\
Propene B & -16.8 & 20.4 & -2.3 & 33.0 & -396.8 \\
cis-2-Butene & -17.5 & 21.5 & -2.9 & 34.0 & -390.5 \\
trans-2-Butene & -16.0 & 22.0 & -1.2 & 34.6 & -393.8 \\
$\mathbf{R}=$ Ac & & & & & \\
Ethene & -25.0 & 15.9 & -12.6 & 27.1 & -329.1 \\
Propene A & -24.3 & 17.4 & -10.8 & 29.5 & -325.9 \\
Propene B & -24.1 & 15.9 & -10.3 & 28.3 & -322.1 \\
cis-2-Butene & -23.2 & 16.9 & -8.9 & 29.3 & -311.3 \\
trans-2-Butene & -23.6 & 17.4 & -9.6 & 29.8 & -313.8 \\
\hline
\end{tabular}

*Energy terms in $\mathrm{kcal} / \mathrm{mol} ; v_{i}$ in $\mathrm{cm}^{-1}$.

to $1.773 \AA$ ). This points to an early transition state for all cases. The $<\mathrm{C} 1-\mathrm{N} 1-\mathrm{C} 2$ angle $\theta_{1}\left(30.7\right.$ to $\left.36.0^{\circ}\right)$ in TS1 contrasted with the $\theta_{1}$ values (around $60^{\circ}$ ) in the aziridine product also points to this. The $\mathrm{C} \alpha-\mathrm{N} 1-\mathrm{C} 1-$ $\mathrm{C} 2$ dihedral angle $\varphi_{1}\left(85.6\right.$ to $\left.103.4^{\circ}\right)$ indicates the $\mathbf{R}$ group is approximately perpendicular to the N1-C1-C2 plane. The N2-N1-C1-C2 dihedral $\varphi_{2}$ values show that the dinitrogen moiety has its $\mathrm{N} 2$ atom within the N1C1-C2 plane for the $\mathrm{HN}_{3}$ cases, but out of the plane for the $\mathrm{MeN}_{3}$ and $\mathrm{AcN}_{3}$ cases. The prediction of early character for TS1 accords well with Hammond's postulate for these exothermic reactions.

\subsection{Two-phase aziridination by azide (Route II)}

The two phases for Route II (Figures 3 and 4) are (a) 1,3-dipolar cycloaddition between azide and alkene via transition state TS2 to form a triazoline, and (b) decomposition of triazoline to yield aziridine in two steps triazoline ring cleavage via TS3, followed by cyclization of the intermediate via TS4.

3.2a Phase (a): Table 2 presents values of the energy changes $\Delta E_{r}$ and $\Delta G_{r}$ with the activation barriers $\Delta E^{\ddagger}$ and $\Delta G^{\ddagger}$ for 1,3-dipolar cycloaddition, and $v_{i}$, the imaginary frequency involved. The reaction energy change is modest ( $\Delta E_{r}$ from -14.0 to $-25.0 \mathrm{kcal} / \mathrm{mol}$, and $\Delta G_{r}$ from -0.0 to $\left.-12.6 \mathrm{kcal} / \mathrm{mol}\right)$. Thermodynamic facility falls in the order $\mathrm{Ac}>\mathrm{Me}>\mathrm{H}$, indicating the acetyl substituent facilitates this step. Successive methyl 
Table 3. B3LYP/6-31G** values of energy parameters* for two-step decomposition of the triazoline intermediate to yield aziridine and dinitrogen via TS3 and TS4 (Figure 4).

\begin{tabular}{lcccccccc}
\hline Alkene & $\Delta E_{r}(1)$ & $\Delta E^{\ddagger}(1)$ & $\Delta G_{r}(1)$ & $\Delta G^{\ddagger}(1)$ & $\Delta E_{r}(2)$ & $\Delta E^{\ddagger}(2)$ & $\Delta G_{r}(2)$ & $\Delta G^{\ddagger}(2)$ \\
\hline $\mathbf{R}=\mathbf{H}$ & & & & & & & & \\
Ethene & -49.0 & 33.9 & -61.1 & 32.7 & 22.4 & 88.8 & 23.2 & 89.0 \\
Propene A & -51.8 & 31.6 & -64.3 & 30.2 & 17.8 & 85.9 & 18.7 & 86.4 \\
$\begin{array}{l}\text { Propene B } \\
\text { cis-2-Butene }\end{array}$ & -46.1 & 33.2 & -58.4 & 32.1 & 23.7 & 89.1 & 24.8 & 90.2 \\
trans-2-Butene & -48.5 & 31.1 & -61.5 & 29.3 & 19.2 & 82.6 & 20.6 & 83.5 \\
$\mathbf{R}=$ Me & & & -61.3 & 30.6 & 19.4 & 81.3 & 20.6 & 82.5 \\
Ethene & -49.0 & 33.8 & -61.2 & 32.4 & 23.6 & 86.7 & 24.7 & 86.8 \\
Propene A & -49.4 & 31.1 & -63.2 & 29.3 & 18.5 & 78.3 & 19.7 & 78.7 \\
Propene B & -45.7 & 34.8 & -58.1 & 33.3 & 21.3 & 87.1 & 23.9 & 89.3 \\
cis-2-Butene & -45.4 & 33.9 & -58.8 & 32.0 & 16.9 & 79.3 & 18.9 & 80.6 \\
trans-2-Butene & -46.5 & 33.3 & -59.7 & 31.7 & 19.8 & 79.2 & 21.6 & 80.5 \\
$\mathbf{R}=$ Ac & & & & & & & & \\
Ethene & -42.1 & 31.1 & -54.2 & 29.7 & 19.9 & 82.8 & 20.6 & 86.8 \\
Propene A & -38.3 & 27.1 & -50.6 & 25.3 & 14.4 & 71.4 & 15.5 & 72.6 \\
$\begin{array}{l}\text { Propene B } \\
\text { cis-2-Butene }\end{array}$ & -38.1 & 30.5 & -49.4 & 29.1 & 15.2 & 72.3 & 16.1 & 73.4 \\
trans-2-Butene & -45.9 & 27.6 & -54.9 & 25.5 & 15.2 & 75.2 & 16.4 & 80.7 \\
\hline
\end{tabular}

*All energy terms in $\mathrm{kcal} / \mathrm{mol}$.

substitution on the alkene reduces reaction facility, attributable to steric effects. The reaction energy change $\Delta E_{r}$ for $\mathrm{MeN}_{3}$ addition to ethene $(-18.9 \mathrm{kcal} / \mathrm{mol})$ may be compared with other estimates ${ }^{22}$ (in $\mathrm{kcal} / \mathrm{mol}$ ) as follows: AM1 (-25.2); B3LYP/6-311++G** (-21.7); HF/6-31G* (-32.7); MP2/6-31G* (-26.1); B3LYP/6$31 \mathrm{G}^{*}(-27.9)$; MP2/6-311++G** (-25.4); B3LYP/6$31 G^{* *} / / A M 1(-25.8)$; QCISD/6-31G* (-31.8). In general, our $\Delta E_{r}$ value is on the smaller side.

The cycloaddition barriers $\Delta E^{\ddagger}(15.9$ to $23.4 \mathrm{kcal} /$ $\mathrm{mol}$ ) are lower by $11-12 \mathrm{kcal} / \mathrm{mol}$ than the free energy barriers $\Delta G^{\ddagger}$. The barriers follow the order $\mathrm{H}>\mathrm{Me}>$ Ac. The kinetic facility order is the same as that for the thermodynamic facility. The acetyl substituent enhances kinetic facility by stabilizing the transition state TS1 through resonance delocalization.

Successive methyl substitution on the alkene increases the barrier, diminishing kinetic as well as the thermodynamic facility. Our $\Delta E^{\ddagger}$ value of $19.0 \mathrm{kcal} / \mathrm{mol}$ for $\mathrm{MeN}_{3}$ cycloaddition to ethene compares with other estimates $^{22}$ (in kcal/mol) as follows: AM1 (36.4); B3LYP/6-311++G** (19.7); HF/6-31G* (22.5); MP2/631G* (17.8); B3LYP/6-31G* (15.9); MP2/6-311++G** (11.2); B3LYP /6-31G**// AM1 (27.8) and QCISD/6$31 \mathrm{G}^{*}$ (24.7). Our estimate is lower than the QCISD estimate $(24.7 \mathrm{kcal} / \mathrm{mol})$, but higher than the MP2/6$311++\mathrm{G}^{* *}$ estimate. 1,3-Dipolar cycloaddition to alkynes leads to barriers lower than for alkenes, where our value for $\mathrm{MeN}_{3}$ addition to ethyne $(15.0 \mathrm{kcal} / \mathrm{mol})$ is comparable with the low B3LYP values of 11.4 and $12.8 \mathrm{kcal} / \mathrm{mol}[6-311+\mathrm{G}(\mathrm{d}, \mathrm{p})$ and $6-311+\mathrm{G}(3 \mathrm{df}, 2 \mathrm{p})$ basis sets respectively] for [2+3] cycloaddition between cyclooctyne and phenyl azide. ${ }^{28}$

B3LYP/6-31G** values of geometry parameters* for TS2 defined in Figure $5 \mathrm{~b}$ are given in Table S2 (SI). The long forming $\mathrm{C} 1-\mathrm{N}$ and $\mathrm{C} 2-\mathrm{N}$ bond lengths $R_{1}$ and $R_{2}(2.156$ to $2.281 \AA$ Á) suggest early transition states in line with the exothermicity of these reactions. The N1$\mathrm{N} 2-\mathrm{N} 3$ angle $\theta_{1}\left(134.5\right.$ to $\left.137.6^{\circ}\right)$ suggests the $\mathrm{N} 2$ atom is between $s p$ and $s p^{2}$. The N2-N1-C $\alpha / \mathrm{H}$ angle $\theta_{2}$ point to an $s p^{3} \mathrm{~N} 1$ atom for the $\mathrm{HN}_{3}$ cases, but an $s p^{2} \mathrm{~N} 1$ atom for the $\mathrm{MeN}_{3}$ and $\mathrm{AcN}_{3}$ cases. The [H/C $\left.\alpha-\mathrm{N} 1-\mathrm{N} 3-\mathrm{N} 2\right]$ dihedral angle $\varphi_{1}$ and the $[\mathrm{H} / \mathrm{C} \alpha-\mathrm{C} 1-\mathrm{C} 2-\mathrm{N} 3]$ dihedral angle $\varphi_{2}\left(132.8\right.$ to $\left.159.1^{\circ}\right)$ predict the $\mathrm{H}$ and Me groups are out of the $\mathrm{C} 1-\mathrm{C} 2-\mathrm{N} 3-\mathrm{N} 2-\mathrm{N} 1$ ring plane. $\varphi_{1}$ and $\varphi_{2}$ values close to $180^{\circ}$ predict the acetyl group is within this ring plane since the Ac group resonates with the ring pi electrons (a stabilizing feature).

3.2b Phase (b): The second phase of 1,3-dipolar cycloaddition of $\mathrm{MeN}_{3}$ to $\mathrm{C}_{60}$ with the elimination of $\mathrm{N}_{2}$ from the triazoline intermediate to yield aziridine had been studied by semi-empirical and DFT methods earlier. ${ }^{30}$ Since our alkene systems have no supporting framework like that present in $\mathrm{C}_{60}$, there is no scope to treat thermal $\mathrm{N}_{2}$ elimination from the triazoline intermediate in a concerted fashion. Our attempts to force this reaction as a concerted adiabatic process did not lead to any transition state. Hence our proposal for a two-step process via two successive 1,2-hydride shifts 
Table 4. B3LYP/6-31G** values* for the highest point along each of the four routes for thermal uncatalyzed aziridination of 4 alkenes by 3 azides $\mathbf{R N}_{3}$.

\begin{tabular}{lcccc}
\hline Reactants & Route A & Route B & Route I & Route II \\
\hline HN $_{3}$ & & & & \\
Ethene & 52.7 & 52.7 & 38.2 & 20.6 \\
Propene & 52.7 & 52.7 & 37.4 & 21.9 \\
cis-2-Butene & 52.7 & 52.7 & 36.4 & 23.3 \\
trans-2-Butene & 52.7 & 52.7 & 36.9 & 23.4 \\
MeN $_{3}$ & & & & \\
Ethene & 39.4 & 39.4 & 38.5 & 19.0 \\
Propene & 39.4 & 39.4 & 38.2 & 20.6 \\
cis-2-Butene & 39.4 & 39.4 & 41.2 & 21.5 \\
trans-2-Butene & 39.4 & 39.4 & 43.2 & 22.0 \\
AcN & & & & \\
Ethene & 28.1 & 28.1 & 38.4 & 15.9 \\
Propene & 28.1 & 28.1 & 35.8 & 17.4 \\
cis-2-Butene & 28.1 & 28.1 & 31.5 & 16.9 \\
trans-2-Butene & 28.1 & 28.1 & 32.5 & 17.4 \\
\hline
\end{tabular}

*All energy terms in $\mathrm{kcal} / \mathrm{mol}$.

(Figure 4) involving an $\mathrm{N}$-alkylimine intermediate. ${ }^{30}$ Decomposition of triazoline to aziridine and $\mathrm{N}_{2}$ may, however, be concerted under photochemical conditions. ${ }^{40}$

Values of the reaction energy changes $\Delta E_{r}(1)$ and $\Delta G_{r}(1)$ and the barriers $\Delta E^{\ddagger}(1)$ and $\Delta G^{\ddagger}(1)$ are given in Table 3 for the first step of phase (b) of Route II. Rearrangement of the triazoline is exother$\operatorname{mic}\left(\Delta E_{r}=-38.1\right.$ to $-51.8 \mathrm{kcal} / \mathrm{mol} ; \Delta G_{r}=$ -49.4 to $-64.3 \mathrm{kcal} / \mathrm{mol}$ ), being less pronounced for the $\mathrm{AcN}_{3}$ cases due to stabilization of the triazoline intermediate by the acetyl group through resonance. The propene A case is favored thermodynamically and kinetically over the propene B case due to steric effects.

Geometry parameters for TS3 (Figure 5c) for triazoline decomposition are given in Table S3 (SI). $R_{1}$ and $R_{2}$ represent lengths of the cleaving $\mathrm{N} 1-\mathrm{N}$ and $\mathrm{C} 1-\mathrm{H}^{*}$ bonds $\left(\mathrm{H}^{*}\right.$ is the migrating hydride atom), and $R_{3}$ represents the length of the forming $\mathrm{C} 2-\mathrm{H}^{*}$ bond. Since this first step is exothermic, TS3 is expected to be "early". Now the N1-N bond lengths $R_{1}$ do not point to an early transition state. However, the cleaving $\mathrm{C} 1-$ $\mathrm{H}^{*}$ bond length $R_{2}(1.110$ to $1.160 \AA$ ) is short, while the forming C2-H bond length $R_{3}(1.710$ to $1.958 \AA$ ) is long. It is the $\mathrm{C}-\mathrm{H}$ bonds involved in 1,2-hydride shift which determine the "early" character of TS3, rather than loss of the $\mathrm{N}_{2}$ moiety. The acute $\mathrm{C} 1-\mathrm{H}^{*}-\mathrm{C} 2$ angle $\theta\left(47.9\right.$ to $\left.58.0^{\circ}\right)$ also shows early character.

Transition state TS4 for the second step of phase (b) has geometry parameters given in Table S4 (SI). The 1,2-hydride shift cum cyclization is endothermic, so transition state TS4 is expected to be 'late.' The forming $\mathrm{N}-\mathrm{C}$ bond length $R_{1}$ between the apical N-atom
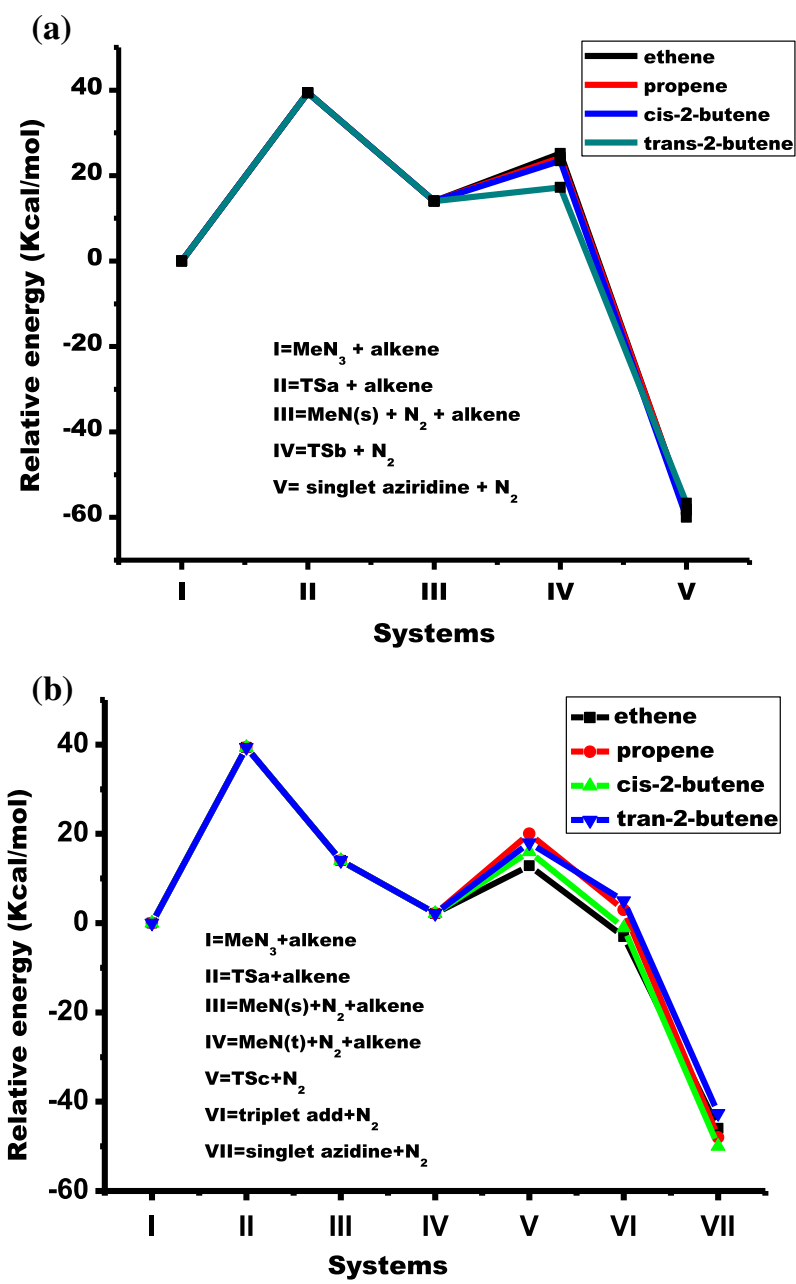

Figure 6. Energy profiles for thermal gas-phase aziridination of alkenes by methyl azide, as given by (a) Route A, and (b) Route $\mathrm{B}$, both involving the discrete nitrene intermediate (results of earlier work ${ }^{15}$ using the B3LYP/6-31G** method). (a) Route A (b) Route B.

and the $\mathrm{C} 2$ atom (2.307 to $2.426 \AA$ ) is longer than this length $(\sim 1.47 \AA)$ in the aziridine product, which indicates early character. The acute $\mathrm{C} 1-\mathrm{N}-\mathrm{C} 2$ bond angle $\theta_{1}$ ( 31.7 to $37.2^{\circ}$ ) compared to the $\sim 60^{\circ}$ values in the aziridine product also indicates the same. So, the cyclization process does not contribute to the late character. However, the forming $\mathrm{C} 1-\mathrm{H}^{*}$ bond length $R_{2}$ is short (1.113 to $1.167 \AA$ ) while the breaking $\mathrm{C} 2-\mathrm{H}^{*}$ bond length $R_{3}$ is long (1.769 to $2.092 \AA$ ), pointing to the late character for TS4. The $\mathrm{C} 1-\mathrm{H}^{*}-\mathrm{C} 2$ bond angle $\theta_{2}\left(41.1\right.$ to $\left.55.3^{\circ}\right)$ is also less acute. It is thus the 1,2-hydride migration process which determines the late character of TS4, not the cyclization process.

\subsection{Comparison of four aziridination mechanisms}

This work, together with an earlier one, delineates four distinct mechanisms for gas phase aziridination of 

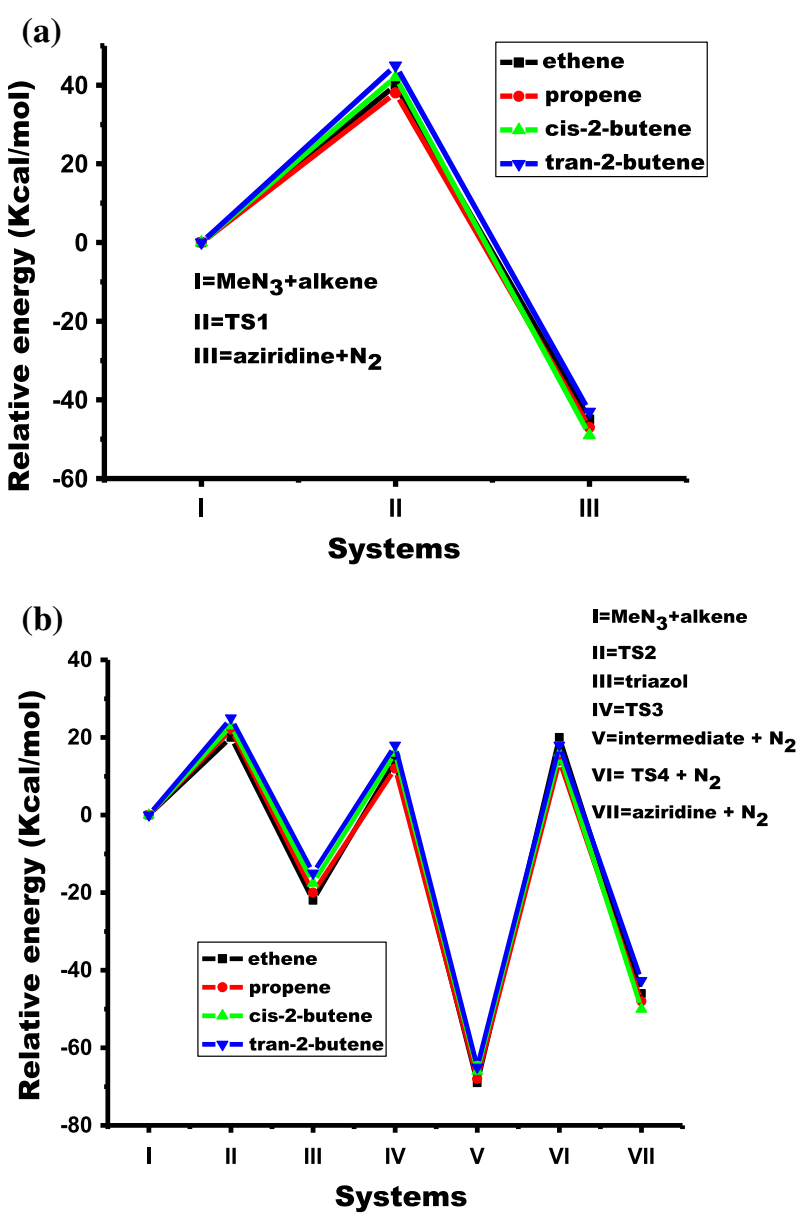

Figure 7. Energy profiles for thermal gas-phase aziridination of alkenes by methyl azide, as given by (a) Route I, and (b) Route II, both involving the whole azide reactant molecule (results of this work using B3LYP/6-31G** method). (a) Route I (b) Route II.

alkenes by azides - Route I and Route II (involving whole azide molecules), and Route A and Route B of the earlier study ${ }^{15}$ (involving discrete nitrene intermediates). We compare the energy profiles of all four pathways to predict the most favorable. Table 4 lists the energy level of the highest point along each route for the three azide reactants $\mathbf{R N}_{3}(\mathbf{R}=\mathrm{H}, \mathrm{Me}, \mathrm{Ac})$ reacting with the four alkene substrates.

Figure 6a depicts the energy profiles for Route A involving singlet nitrene generation via transition state TSa followed by singlet nitrene addition to alkene via transition state TSb. Figure $6 \mathrm{~b}$ shows the energy profiles for multi-step Route B involving azide decomposition to singlet nitrene, singlet to triplet conversion, triplet nitrene addition to alkene via TSc, and triplet to singlet conversion to the aziridine product. Figures $6 \mathrm{a}$ and $6 \mathrm{~b}$ portray only the cases for $\mathrm{MeN}_{3}$. For both Route A and Route $\mathrm{B}$, the highest point concerns only the azide reactant decomposition to the singlet nitrene $\mathrm{RN}$, being the same for all alkene substrates.
Figure 7a portrays energy profiles for Route I, while Figure $7 \mathrm{~b}$ gives energy profiles for Route II, depicting the cases for methyl azide. The highest point for Route I is TS1 for whole azide concerted addition to alkene forming aziridine. For Route II, involving transition states TS2, TS3 and TS4, the highest point is TS2 for 1,3-dipolar cycloaddition of azide to alkene.

We infer from Table 4 that gas phase thermal aziridination of alkenes by azides is most feasible by the multi-step Route II involving initial 1,3-dipolar cycloaddition of the whole azide to alkene. This entails an energy requirement of 15.9 to $23.4 \mathrm{kcal} / \mathrm{mol}$. We thus conclude that gas phase aziridination of alkenes under thermal conditions would most easily proceed by a mechanism involving prior 1,3-dipolar cycloaddition between azide and alkene.

\section{Conclusions}

This DFT B3LYP/6-31G** study on azide addition to alkenes forming aziridines by two distinct mechanisms (Routes I and II) leads to the following conclusions:

1. Route I by direct concerted addition-elimination of azide to alkene (studied here for the first time) involves appreciable barriers, being assisted by methyl substitution on the alkene, showing the azide to have electrophilic character.

2. The first step of Route II (1,3-dipolar cycloaddition of azide to alkene) yields appreciable barriers ( 15.9 to $23.4 \mathrm{kcal} / \mathrm{mol}$ ) and the facility order Ac > $\mathrm{Me}>\mathrm{H}$ with respect to azide substituent $\mathrm{R}$, but is not assisted by methyl substitution on the alkene.

3. The second phase of Route II involves an Nalkylimine intermediate which cyclizes to the aziridine product by two successive hydride shifts. It is these hydride shifts that contribute significantly to the late character of the transition states involved.

4. Concerted decomposition of the 1,3-dipolar cycloaddition product is exothermic with appreciable barriers $(27.1$ to $33.9 \mathrm{kcal} / \mathrm{mol})$ and assisted by methyl substitution on the initial alkene reactant.

5. The endothermic final step of Route II (cyclization of $\mathrm{N}$-alkylimine to aziridine) involves very high barriers, accompanied by appreciable net energy lowering for the second phase of Route II.

6. The geometries of the various transition states for the various concerted steps are characterized as 'early' or 'late' in good accord with Hammond's postulate.

7. Of all four routes examined for aziridination of alkenes by azides, Route II involving 1,3-dipolar cycloaddition between azide and alkene is predicted as most favorable. 


\section{Supplementary Information (SI)}

Supplementary Information is available at www.ias.ac.in/ chemsci.

\section{Acknowledgements}

S. P. D. thanks the University Grants Commission for financial assistance through the UGC Research Fellowship for Meritorious Students.

\section{References}

1. Padwa A and Murphree S S 2006 Epoxides and aziridines - a mini review ARKIVOC 36

2. Hennessy J 2014 Aziridine synthesis Nature Chem. 6 168

3. Bellavia-Lund C and Wudl F 1997 Synthesis of [70] azafulleroids: Investigations of azide addition to $\mathrm{C}_{70} \mathrm{~J}$. Am. Chem. Soc. 119943

4. Averdung J, Luftmann H, Mattay J, Claus K and Abraham W 1995 Synthesis of 1,2-(2,3-dihydro-1 H-azirino)[60]fullerene, the parent fulleroaziridine Tetrahedron Lett. 362957

5. Scriven E F V and Turnbull C K 1988 Azides: Their preparation and synthetic uses Chem. Rev. 88297

6. Carmen Gil S B, Knepper K and Zimmermann V 2005 Organic azides: An exploding diversity of a unique class of compounds Angew. Chem. Int. Ed. 445188

7. Pellisier H 2014 Recent developments in asymmetric aziridination Adv. Synth. Catal. 3561899

8. Osborn H M I and Sweeney J 1997 The asymmetric synthesis of aziridines Tetrahedron Asymmetry 111693

9. Xue Z, Louisa V M D, Weeks J H, Whittlesey B R and Mayer M F 2010 Asymmetric aziridination of Ntert-butanesulfinyl imines with phenyldiazomethane via sulfur ylides ARKIVOC 765

10. Janardanan D and Sunoj R B 2008 Enantio- and diastereoselectivities in chiral sulfur ylide promoted asymmetric aziridination reactions J. Org. Chem. 738163

11. Aggarwal V K, Alsonso E, Fang G, Ferrara M, Hynd G and Porcelloni M 2001 Application of chiral sulfides to catalytic asymmetric aziridination and cyclopropanation with in situ generation of the diazo compound Angew. Chemie Int. Ed. 401433

12. Li Z, Conser K R and Jacobsen E N 1993 Asymmetric alkene aziridination with readily available chiral diimine-based catalysts J. Am. Chem. Soc. 1155326

13. Li Z, Quan R W and Jacobsen E N 1995 Mechanism of the (diimine)copper-catalyzed asymmetric aziridination of alkenes. Nitrene transfer via ligand-accelerated catalysis J. Am. Chem. Soc. 1175889

14. Wu H, Xu L-W, Xia C-G, Ge J and Yang L 2005 Convenient metal-free aziridination of alkenes with chloramine-T using tetrabutylammonium iodide in water Synth. Comm. 391413

15. Devi S P, T Salam and Duncan Lyngdoh R H 2016 Uncatalyzed thermal gas phaseaziridination of alkenes by organic azides. Part I: Mechanisms with discrete nitrene species J. Chem. Sci. 128681
16. Padwa A and Pearson W H (Eds.) 2002 Synthetic applications of 1,3-dipolar cycloaddition chemistry toward heterocycles and natural products In The Chemistry of Heterocyclic Compounds Vol. 59 (New York: Wiley)

17. Sha C K and Mohanakrishnan A K 2002 Azides in synthetic applications of 1,3-dipolar cycloaddition chemistry towards heterocycles and natural products Vol $59 \mathrm{~A}$ Padwa and W H Pearson (Eds.) (New York: Wiley)

18. Huisgen R 1961 Centenary lecture - 1,3-dipolar cycloadditions Proc. Chem. Soc. London 357

19. Meldal M and Tornoe C W 2008 Cu-catalyzed azidealkyne cycloaddition Chem. Rev. 1082952

20. Kolb H C, Finn M G and Sharpless K B 2001 Click chemistry: diverse chemical function from a few good reactions Angew. Chem. Int. Ed. 402004

21. Baskin J M, Prescher J A, Laughlin S T, Agard N J, Chang P V, Miller I A, Lo A, Codelli J A and Bertozzi C R 2007 Copper-free click chemistry for dynamic in vivo imaging Proc. Natl. Acad. Sci. USA 10416793

22. Ess D H and Houk K N 2008 Theory of 1,3dipolar cycloadditions: Distortion/interaction and frontier molecular orbital models J. Am. Chem. Soc. 130 10187

23. Chen X F, Yang K and Han K L 2009 Theoretical study of 1,3-dipolar cycloaddition of hydrazoic acid to substituted ynamines Chin. J. Chem. Phys. 2243

24. Schoenebeck F, Ess D H, Jones G O and Houk K N 2009 Reactivity and regioselectivity in 1,3dipolar cycloadditions of azides to strained alkynes and alkenes: A computational study J. Am. Chem. Soc. 131 8121

25. Karmakar S and Datta A 2015 Metal-free azide-alkyne click reaction: role of substituents and heavy atom tunneling J. Phys. Chem. B 11911540

26. Washington I and Houk K N 2003 Strategies for the design of organic aziridination reagents and catalysts: Transition structures for alkene aziridinations by $\mathrm{NH}$ transfer J. Org. Chem. 636497

27. Almahy H A and Elhassan E 2013 Spectrospic study of 1,3-dipolar cycloaddition reaction of benzyl azide and acrylic acid Int. J. Chem. Sci. 111

28. Bach R D 2009 Ring strain energy in the cyclooctyl system. The effect of strain energy on [3+2] cycloaddition reactions with azides J. Am. Chem. Soc. 131 5233

29. Zeghada A, Bentabed-Ababsa G, Derdour A, Abdelmounim S, Domingo L R, S'aez J A, Roisnel T, Nassare $\mathrm{E}$ and Mongin F 2011 A combined experimental and theoretical study of the thermal cycloaddition of aryl azides with activated alkenes Org. Biomol. Chem. 9 4295

30. Cases M, Duran M, Mestres J, Martin N and Sola M 2001 Mechanism of the addition reaction of alkyl azides to [60]fullerene and the subsequent $\mathrm{N}_{2}$ extrusion to form monoimino-[60]fullerenes J. Org. Chem. 66433

31. Janardanan D and Sunoj R B 2007 Computational investigations on the general reaction profile and diastereoselectivity on sulfur ylide promoted aziridination Chem. Eur. J. 134805

32. Rajeev R and Sunoj R B 2011 Mechanism and electronic effects in nitrogen ylide-promoted asymmetric aziridination reaction Org. Biomol. Chem. 92123 
33. Jaccob M and Venuvanalingam P 2011 Computational insights into the roles of steric and electrostatic interactions in arsenic ylide mediated aziridination reactions Eur. J. Org. Chem. 3458

34. Kalaiselvan A and Venuvanalingam P 2007 Ring opening of boriranes vis-à-vis aziridines: $A n$ ab initio and DFT probe on the mechanisms Int. J. Quantum Chem. 1071590

35. Lee C, Yang W and Parr R G 1988 Development of the Colle-Salvetti correlation-energy formula into a functional of the electron density Phys. Rev. B 37785

36. Becke A D 1993 A new mixing of Hartree-Fock and local density-functional theories J. Chem. Phys. 98 1372

37. Scott A P and Radom L 1996 Harmonic vibrational frequencies: An evaluation of Hartree-Fock, MøllerPlesset, quadratic configuration interaction, density functional theory and semiempirical scale factors $J$. Phys. Chem. 10016502

38. Frisch M J, Trucks G W, Schlegel H B, Scuseria G E, Robb M A, Cheeseman J R, Scalmani G, Barone V,
Mennucci B, Petersson G A, Nakatsuji H, Caricato M, Li X, Hratchian H P, Izmaylov A F, Bloino J, Zheng G, Sonnenberg J L, Hada M, Ehara M, Toyota K, Fukuda R, Hasegawa J, Ishida M, Nakajima T, Honda Y, Kitao O, Nakai H, Vreven T, Montgomery J A, Peralta J E, Ogliaro F, Bearpark M, Heyd J J, Brothers E, Kudin K N, Staroverov V N, Keith T, Kobayashi R, Normand J, Raghavachari K, Rendell A, Burant J C, Iyengar S S, Tomasi J, Cossi M, Rega N, Millam J M, Klene M, Knox J E, Cross J B, Bakken V, Adamo C, Jaramillo J, Gomperts R, Stratmann R E, Yazyev O, Austin A J R, Pomelli C C, Ochterski J W, Martin R L, Morokuma K, Zakrzewski V G, Voth G A, Salvador P, Dannenberg J J, Dapprich S, Daniels A D, Farkas O, Foresman J B, Ortiz J V, Cioslowski J, Fox D J, Gaussian, Inc., Wallingford CT, Gaussian 09, Revision C.01, 2010

39. Hammond G S 1955 A correlation of reaction rates $J$. Am. Chem. Soc. 77334

40. Burgess E M, Carithers R and McCullagh L 1968 Photochemical decomposition of $1 \mathrm{H}$-1,2,3-triazole derivatives J. Am. Chem. Soc. 901923 